\title{
An Enhanced System for Allocation of Resources in Nigerian Universities
}

\author{
Rhoda Ikono \\ Department of \\ Computer Science \\ and Engineering, \\ Obafemi Awolowo \\ University, lle-Ife, \\ Nigeria.
}

\author{
Abimbola \\ Babalola \\ Department of \\ Computer Science \\ and Engineering, \\ Obafemi Awolowo \\ University, lle-Ife, \\ Nigeria.
}

\author{
Olaronke Iroju \\ Department of \\ Computer Science, \\ Adeyemi College of \\ Education, Ondo, \\ Nigeria.
}

\author{
Ishaya Gambo \\ Department of \\ Computer Science \\ and Engineering, \\ Obafemi Awolowo \\ University, lle-Ife, \\ Nigeria.
}

\begin{abstract}
Education is a fundamental right and access to higher education plays a vital role in shaping an individual's career in life. However, the process of securing admission into Nigerian universities is highly competitive. This is because the population of students who seek admission into Nigerian Universities annually is exponential. Nevertheless, one of the majors of securing admission into Nigerian Universities is through the pre-degree program. This process is however manually done, time consuming and fraught with errors. Consequently, this paper designs an enhanced system that automatically allocates courses to students seeking admission into Nigerian Universities through the pre-degree program. The system uses artificial neural network for its decision making capabilities. This will help to eliminate bias that unaided human judgment is prone to during admission process.
\end{abstract}

\section{General Terms}

Artificial Intelligence, Machine Learning, Algorithm

\section{Keywords}

Resource Allocation System, Course of Study, Pre-Degree, Resource Allocation.

\section{INTRODUCTION}

Education is very vital to the development of any nation. It is very critical to a country's economic strength and social well-being [1]. It is a tool that aids rapid development. There are three different stages involved in attaining education in Nigeria. These include the Primary Education, Secondary Education and Tertiary or Higher Education. Of these three, the stage that influences an individual's career path is the higher education. The tertiary or higher education is usually achieved in universities, polytechnics and colleges of educations. These institutions contains academic resources that are utilized for the development of students. These resources include academic resources such as instructional materials, offered degrees, course structure and curricula, enrollment and retention [2]. An offered degree is awarded in a certain course of study therefore it is considered an academic resource allocated to newly admitted students [3].

In Nigeria, the main channel of seeking admission into the university is through the Unified Tertiary Matriculation Examination (UTME) conducted by the Joint Admission and Matriculation Board (JAMB) [4]. This is to ensure a unified standard for the conduct of matriculation examination and the placement of suitably qualified candidates into the nation's higher education system. However, the number of applicants who seek admission into these universities through this medium grow exponentially every year [5], less than 20 percent of these applicants are admitted into the university [6]. The remaining unsuccessful candidates seek for alternative means of entry into the university [3]. An example of such alternative means is the Pre-Degree program. This program was introduced in Nigerian universities as a result of poor performance in UTME almost every year. The pre-degree program provides alternative for applicants who have failed the unified examination. This process is however manual, time consuming and fraught with errors,

This paper is limited to the admission system of Obafemi Awolowo University through its Pre-Degree program. The pre-degree program runs for a year and it is divided into two contacts. In each of these contacts, candidates are required to take a subject combination. Series of tests and examinations are conducted in subjects of this combination. The average result of these examination for both contacts are computed and this serves as the overall score for each candidate. There is a general cut-off of $60 \%$ which is the minimum overall score expected of a candidate to be eligible for admission consideration. Candidates who score less than $60 \%$ are automatically disqualified from the admission process. The overall score is used to allocate courses of study in the university's undergraduate program. The course(s) of study that are considered for a candidate are from a list of three choices (in preferential order) submitted by the candidate. Nonetheless, the candidate is allocated only one course of study at the end of the admission process. Each course of study has an assigned cut-off score that is compared to the candidate's overall score to determine if the candidate qualifies to the allocated course of study. Students whose overall scores are equal to or higher than the general $60 \%$ benchmark score, but lower than the cutoff mark of the courses of study on their preferred list are randomly assigned a course of study, mostly options that have a very low number of applicants yearly. Figure 1 shows an analysis of the result of candidates in 2014/2015 program. Subjects in each combination are taken along with English language which is a compulsory course for all combinations. This procedure is manual, time consuming, prone to human bias and irregularities. In addition, some of the candidates are offered courses that they consider 
unsatisfactory while some get courses they do not deserve [7] which is sometimes because of familiarity with the admission officer. Hence, this study automates the existing manual process and provides an extension of its functionality by incorporating artificial intelligence to provide decision support abilities.

The proposed system implements a machine learning algorithm that allows computers to learn from past examples using statistical and optimization techniques [8]. The type of machine learning used is the artificial neural network. This is a supervised learning algorithm where the output is supplied along with the input to the system during training [9]. The system uses this learning algorithm to aid the allocation of candidates who score higher than $60 \%$ but whose scores are lower than any of their preferred choices. This system will help to eliminate human bias and relieve the stress involved in the procedure.

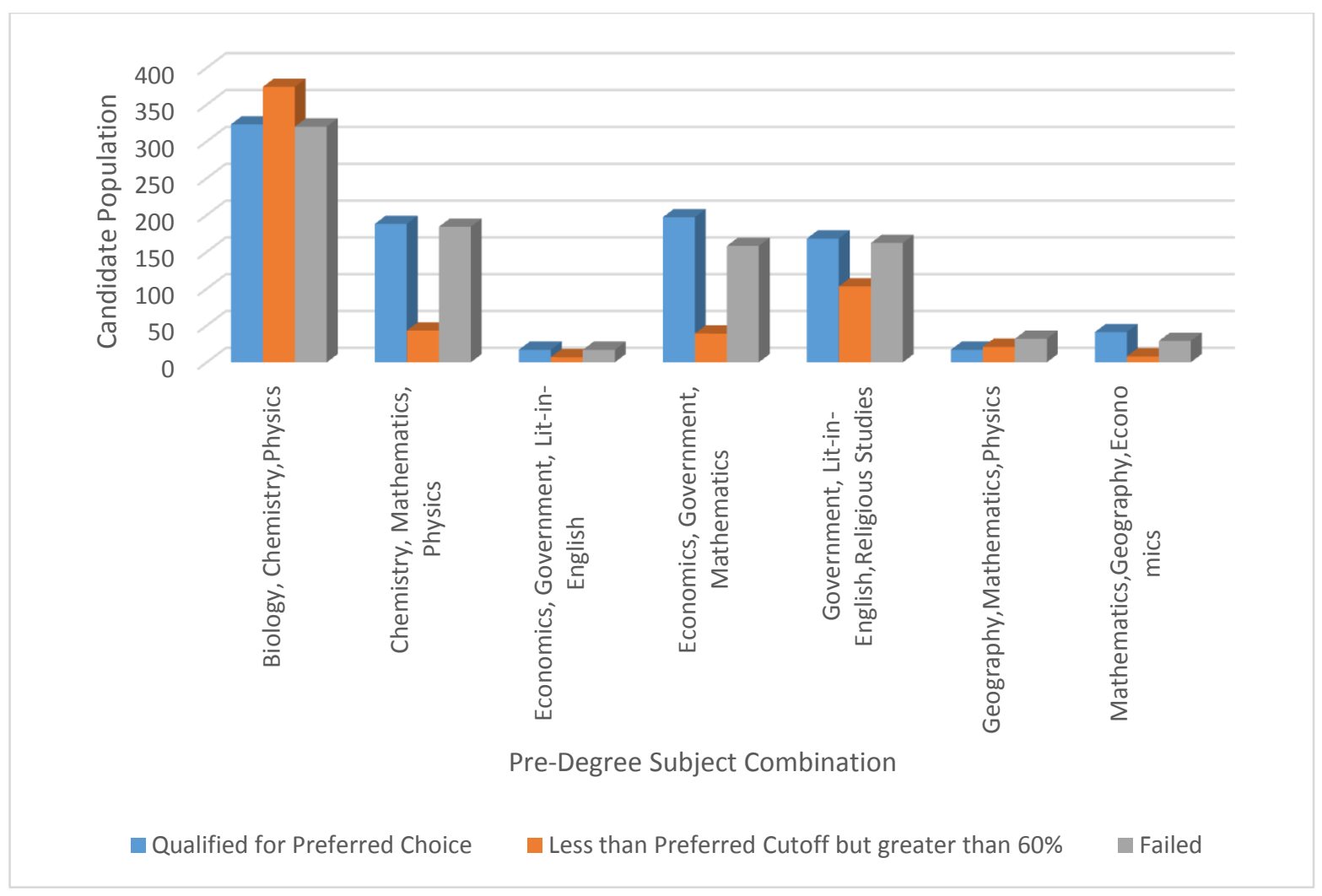

Figure. 1: Result of applicants to the 2014/2015 session of Pre-Degree program at Center for Distance learning (CDL)

Section 2 presents a view of course of study as a resource, Section 3 discusses related works while the proposed system is presented in Section 4. Section 5 discusses the results, Section 6 discusses the evaluation of the performance of the system and the result of the evaluation is presented in Section 7 while the research is concluded in Section 8 .

\section{COURSE OF STUDY AS A RESOURCE}

Resources are assets used to produce goods and services to meet human needs and wants [10]. They are things available for an individual, a group of individuals, an organization, institution, association and any combination thereof, to be used for the purpose of achieving predetermined aims and objectives [11]. A university is an organization that has financial, technological, human and academic resources [2] [12] [13] [14]. Resources often interact to achieve the goal of the institution. A typical interaction is the allocation of funds (financial resources) to cater for staffs' (human resources) salaries. Universities also provide high level of human resources (workers) that drive the economy and ensure rapid transformation in the society by awarding degrees (academic resource) in different course(s) of study (academic resource) [15]. The allocation of this course of study as an academic resource to applicants is the main focus of this study.

\section{RELATED WORKS}

There are some intelligent systems that have been developed to provide support during admission process. Mabu and Muhammed [16] developed a system that helps Nigerian universities in screening students during admission process. The system was developed using ID3 algorithm. The system was implemented using C++ programming language. The study concluded that the use of a decision support system for student enrollment will increase the accuracy and speed of the admission system. The system is mainly interested in identifying the best applicants for admission purpose and gives little or no consideration to others. Ajayi et al. [17] developed a rulebased support system for admission into higher institution of learning. The support system was designed with Unified modelling language tools and the implemented database was designed using MySQL. The study concluded that a support system seems to be the needed shift away from the awkward manual process for admission and recommends its use for a proper, efficient and effective admission 
process management. This system generates the cut-off mark itself based on some defined rules in the system and values supplied which causes continuous change in the requirement without a certain standard. Waters and Miikkulaine [18] developed GRADE, a statistical machine learning system to provide support for the work of the graduate admissions committee at the University of Texas. GRADE uses historical admissions data to predict the probability that the committee will admit a particular applicant. The system makes the review process more efficient by enabling reviewers to spend most of their time on applicants near the decision boundary and by focusing their attention on parts of each applicant's file that matters the most. An evaluation of the system over two sessions of $\mathrm{PhD}$ admissions shows that the system leads to dramatic time savings, reducing the total time spent on reviews by at least $74 \%$ but it is designed only for graduate admissions and undergraduate admission was not considered. Tanna [19] developed a support system that helps candidates decide which field of engineering suit them. The system takes mean of current and previous Common Eligibility Tests (CET) scores of student who applied for that field. The mean is then compared with the candidates score in order to classify him as best bargain, ambitious or safe with respect to that field. In the study, the mean served as a feedback to the system and it was observed using the mean provides a linear feedback which takes the system a long time to self-correct errors. The study showed that arithmetic mean is very sensitive therefore few large values in a sample may lead to the wrong prediction. It also concluded that machine learning techniques are generally better predictors than statistical techniques. The system was developed with the applicants as the end-users to recommend best schools to apply to base on applicant's result. It does not consider the requirement of any institution. All of these systems focus on applicants who are eligible for admission offer based on merit. In this paper, a flexible system that accommodates and considers average candidates for admission is developed.

\section{PROPOSED SYSTEM}

The proposed system is divided into three modules. These include the following:

$$
\begin{aligned}
\text { i. } & \text { Input Module } \\
\text { ii. } & \text { Process Module } \\
\text { iii. } & \text { Output Module }
\end{aligned}
$$

\subsection{Input}

Each applicant seeking admission into the university through the pre-degree program has some data that is used in the procedure. These data are presented in the following formats:

Text data: This represents the applicant's unique identification number and the three preferred courses of study

Numerical data: This represents the overall score obtained by candidate in the program.

These data are presented to the system as the input to be processed

\subsection{Process Module}

When these data are presented to the system, they are processed. During processing, the system compared the input score with the general cutoff loaded from the database of the system. If the score is lower than the general cutoff, the applicants is denied admission otherwise the processing continued to the next stage. The rules used for processing based on the algorithm developed by Ikono $\boldsymbol{e t}$ al. [3] are:

Let $\mathrm{SP}=$ Score percentile

$\mathrm{NA}=$ No Admission

$\mathrm{MP}=$ Most Preferred Course of Study

$M P_{c}=$ Most Preferred Course Cut-off

$\mathrm{NP}=$ Next Preferred Course of Study

$N P_{c}=$ Most Preferred Course Cut-off

LP $=$ Least Preferred Course of Study

$L P_{C}=$ Most Preferred Course Cut-off System

$A C_{R A S}=$ Alternative Course of Study allocated by

Therefore,

$$
\begin{array}{ll}
\mathrm{SP}<60 \rightarrow \mathrm{NA} & \ldots \text { Rule (1) } \\
\mathrm{SP}<=M P_{c} \rightarrow \mathrm{MP} & \ldots \text { Rule (2) } \\
N P_{c}<=S P<M P_{c} \rightarrow \mathrm{NP} & \ldots \text { Rule (3) } \\
L P_{c}<=S P<N P_{c} \rightarrow \mathrm{LP} & \ldots \text { Rule (4) } \\
\mathrm{SP}<\mathrm{LP} \rightarrow A C_{R A S} & \ldots \text { Rule (5) }
\end{array}
$$

Only one of these rules are executed per time based on IF...THEN conditions. Rules 1 - 4 are executed directly when any is applied but Rule 5 involved further processing. Rule 5 is used to determine which course of study will be the best alternative to offer an applicant whose cutoff is lower than all the preferred choices but higher than $60 \%$.

This module allocates a course of study based on the scores obtained in the subjects of a particular pre-degree combination. It uses historical data to aid its decision making process. The historical data used for this system was the 2014/2015 result of candidates who sought admission into the undergraduate program of Obafemi Awolowo University, through the Pre-Degree programme. These data was collected from Center for Distance learning, Obafemi Awolowo University, Moro, Ile-Ife, Osun State, Nigeria. Candidates who originally applied to the faculty of technology of the university and passed the general Pre-degree cutoff but did not qualify for their preferred choices was used as the scope of this research. A dataset set with 150 unique results was created from their result. These results were obtained by calculating the average score for subject in faculty of technology combination (English, Chemistry, Mathematics and Physics) for the two contacts in the programme. For the allocation, courses of study in faculty of Science (Chemistry Department, Geology Department, Physics Department and Mathematics Department) and faculty of Education (Chemistry Education, Mathematics Education and Physics Education Department) were considered.

The dataset of the form $\left\{\left(v_{1}, y_{1}\right), \ldots,\left(v_{k}, y_{k}\right)\right.$ was stored as a Comma Separated Value (CSV) file and divided into two. $80 \%$ (120) was used as the training dataset while $20 \%$ (30) was used as the testing dataset. The training set was used to teach the system how to recognize and learn the existing patterns in various result and the testing data was 
to evaluate how the system applied the learnt pattern to unfamiliar data. During execution, the training set was presented to the system and artificial neural network (machine learning algorithm) was applied to the data such that:

$$
y_{k}=\varphi\left(v_{k}\right)
$$

Where $y_{k}=$ expected course of study to be allocated to an applicant

$v_{k}=$ All of result from each subject of Pre-Degree combination

$\varphi=$ the sigmoid activation function expressed as

$$
\varphi=\frac{1}{1+e^{-x}}
$$

where $\mathrm{x}=v_{k} * \mathrm{w}$

$w \in \mathbb{R}$ is the weight found between connecting neurons. The first values allocated to the weights at first are real values selected at random [20]. These weights were subsequently adjusted for a better output through training. After each adjustment, there was an output $t_{k}$ which

\section{Resource Allocation Manager}

possibly was not identical to output $y_{k}$ and produced an error E. In order to make $t_{k}$ and $y_{k}$ identical, the error E was minimized using back propagation algorithm defined as:

$$
E=\frac{1}{2} \sum_{k=1}^{n}\left\|y_{k}-t_{k}\right\|^{2}
$$

This error E was used to correct the initial weights. This system was implemented with Microsoft C\# programming language using Encog Framework. This framework is a machine learning framework that supports different learning algorithms [21]. It was integrated to provide support for decision making through its specially designed libraries.

\subsection{Output Module}

After the training, the testing data was presented to the system to evaluate its performance whenever it is presented with data that is not part of its training set to prevent over-

\begin{tabular}{|c|c|c|c|c|c|}
\hline & english $(100)$ & chemistry(70) & mathematics $(70)$ & physics (70) & $\begin{array}{l}\text { Course of } \\
\text { study }\end{array}$ \\
\hline \multirow[t]{23}{*}{ b } & 61.0 & 46.5 & 41.0 & 45.0 & Chemistry \\
\hline & 60.5 & 51.5 & 43.5 & 34.5 & Chemisty \\
\hline & 61.5 & 51.0 & 47.5 & 41.0 & Chemisty \\
\hline & 63.0 & 45.0 & 40.5 & 40.5 & Chemistry \\
\hline & 67.0 & 48.5 & 44.5 & 40.5 & Chemisty \\
\hline & 69.5 & 50.5 & 49.0 & 39.0 & Chemisty \\
\hline & 65.5 & 53.0 & 48.5 & 40.5 & Chemisty \\
\hline & 62.5 & 47.0 & 41.5 & 40.5 & Chemisty \\
\hline & 63.0 & 44.0 & 38.0 & 40.5 & Chemistry \\
\hline & 63.5 & 43.5 & 36.5 & 37.0 & Chemisty \\
\hline & 60.0 & 43.5 & 35.0 & 41.0 & Chemisty \\
\hline & 65.5 & 48.0 & 31.0 & 35.5 & Chemisty \\
\hline & 79.5 & 49.0 & 36.0 & 47.5 & Chemistry \\
\hline & 69.5 & 42.0 & 36.5 & 41.0 & Chemistry \\
\hline & 68.0 & 47.0 & 44.5 & 36.5 & Chemisty \\
\hline & 64.0 & 54.0 & 36.0 & 39.0 & Chemistry \\
\hline & 67.5 & 48.0 & 41.5 & 43.0 & Chemisty \\
\hline & 66.5 & 45.5 & 37.0 & 33.5 & Chemisty \\
\hline & 62.0 & 62.0 & 34.5 & 31.0 & Chemisty \\
\hline & 61.5 & 61.5 & 39.5 & 39.0 & Chemisty \\
\hline & 63.5 & 40.5 & 39.5 & 32.5 & Chemistry Educat... \\
\hline & 63.5 & 40.0 & 33.5 & 31.0 & Chemistry Educat... \\
\hline & 62.5 & 39.5 & 30.0 & 33.0 & Chemistry Educat... \\
\hline
\end{tabular}
fitting. Figure 2 is a screenshot of the testing.

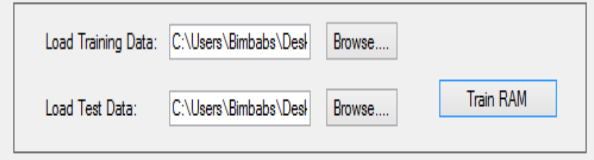

\begin{tabular}{|c|c|c|c|c|c|c|c|}
\hline Input No & Enqlish & Chemistry & Mathematics & Physic: & Ideal Dep & \multicolumn{2}{|c|}{ Assiqned Dept } \\
\hline 1 & 63 & 50.5 & 36.5 & 42 & Chemistry & \multicolumn{2}{|c|}{ Chemistry } \\
\hline 2 & 67.5 & 53 & 43 & 40.5 & Chemistry & \multicolumn{2}{|c|}{ Chemistry } \\
\hline 3 & 60 & 53 & 42 & 46 & Chemistry & \multicolumn{2}{|c|}{ Chemistry } \\
\hline 4 & 64 & 49 & 42 & 50 & Chemistry & \multicolumn{2}{|c|}{ Geology } \\
\hline 5 & 63.5 & 53 & 40.5 & 49 & Chemistry & \multicolumn{2}{|c|}{ Chemistry } \\
\hline 6 & 60.5 & 40.4 & 34 & 34 & \multicolumn{2}{|c|}{ Chemistry Education } & Chemistry Education \\
\hline 7 & 67 & 42 & 39 & 35 & \multirow{2}{*}{\multicolumn{2}{|c|}{ Chemistry Education }} & Chemistry Education \\
\hline 8 & 63.5 & 32.5 & 32 & 31.5 & & & Mathematics Educal \\
\hline 9 & 66.5 & 35 & 33 & 31 & \multicolumn{2}{|c|}{ Chemistry Education } & Chemistry Education \\
\hline & & & & & & & $>$ \\
\hline
\end{tabular}

\section{System Training and Testing Result} Accuracy: $80 \%$

\begin{tabular}{|c|c|c|c|c|c|c|c|}
\hline & Chemisty & $\begin{array}{l}\text { Chemistry } \\
\text { Education }\end{array}$ & Geology & Mathematics & $\begin{array}{l}\text { Mathematics } \\
\text { Education }\end{array}$ & Physics & $\begin{array}{l}\text { Physics } \\
\text { Education }\end{array}$ \\
\hline Chemistry & 4 & 0 & 1 & 0 & 0 & 0 & 0 \\
\hline $\begin{array}{l}\text { Chemisty } \\
\text { Education }\end{array}$ & 0 & 3 & 0 & 0 & 1 & 0 & 0 \\
\hline Geology & 0 & 0 & 3 & 1 & 0 & 0 & 0 \\
\hline Mathematics & 1 & 0 & 0 & 2 & 1 & 0 & 0 \\
\hline $\begin{array}{l}\text { Mathematics } \\
\text { Education }\end{array}$ & 0 & 0 & 0 & 0 & 4 & 0 & 0 \\
\hline Physics & 0 & 0 & 0 & 0 & 0 & 5 & 0 \\
\hline \multirow[t]{2}{*}{$\begin{array}{l}\text { Physics } \\
\text { Eduction }\end{array}$} & 0 & 0 & 0 & 0 & 0 & 1 & 3 \\
\hline & & & & & $\begin{array}{c}\text { Assign } \\
\text { Department }\end{array}$ & Close & \\
\hline
\end{tabular}

Corfusion Matrix

Figure 2. Screenshot of System Training and Testing

The number of correct allocations and incorrect allocations was used to draw a confusion matrix. This matrix shows the allocations made by the system where output by the system $t_{k}$ is the same as output stated in the testing dataset $y_{k}$ and where they differ. The values in this matrix was used to calculate performance indicators. Table 1 shows the confusion matrix. 


\section{RESULT}

The training dataset used had 120 instances with each course of study with the following number of unique combinations: Chemistry - 20, Chemistry Education - 15, Geology - 16, Mathematics - 18, Mathematics Education 14, Physics - 20 and Physics Education - 17. The test dataset comprised of the following: Chemistry - 5, Chemistry Education - 4, Geology - 4, Mathematics - 4, Mathematics Education - 4, Physics - 5 and Physics Education - 4. Based on the recommendation of Hall and Holmes [22], the training and testing was repeated five times with the order of the training set randomized. The average of result of these tests was used as the final result. This result are: out of the 5 instances of chemistry, the system misallocated 1 to Geology while the remaining 4 were correctly allocated to Chemistry. Of the 4 instances of Chemistry Education, 1 was misallocated to Mathematics Education and remaining 2 were correctly allocated. Out of 4 instances of Geology, 1 was incorrectly allocated to Mathematics and 3 was correctly allocated. For Mathematics, 2 were correctly allocated while 1 was wrongly allocated to Mathematics Education and Chemistry each. For Mathematics Education, all of the 4 instances were correctly allocated. All of the 5 instances for Physics were also correctly allocated while out of the 4 instances for physics education, 1 was misallocated to physics and the remaining 3 were correctly allocated. This made the total number of correct to 24 and incorrect allocation to 6 .

Table 1. Confusion Matrix

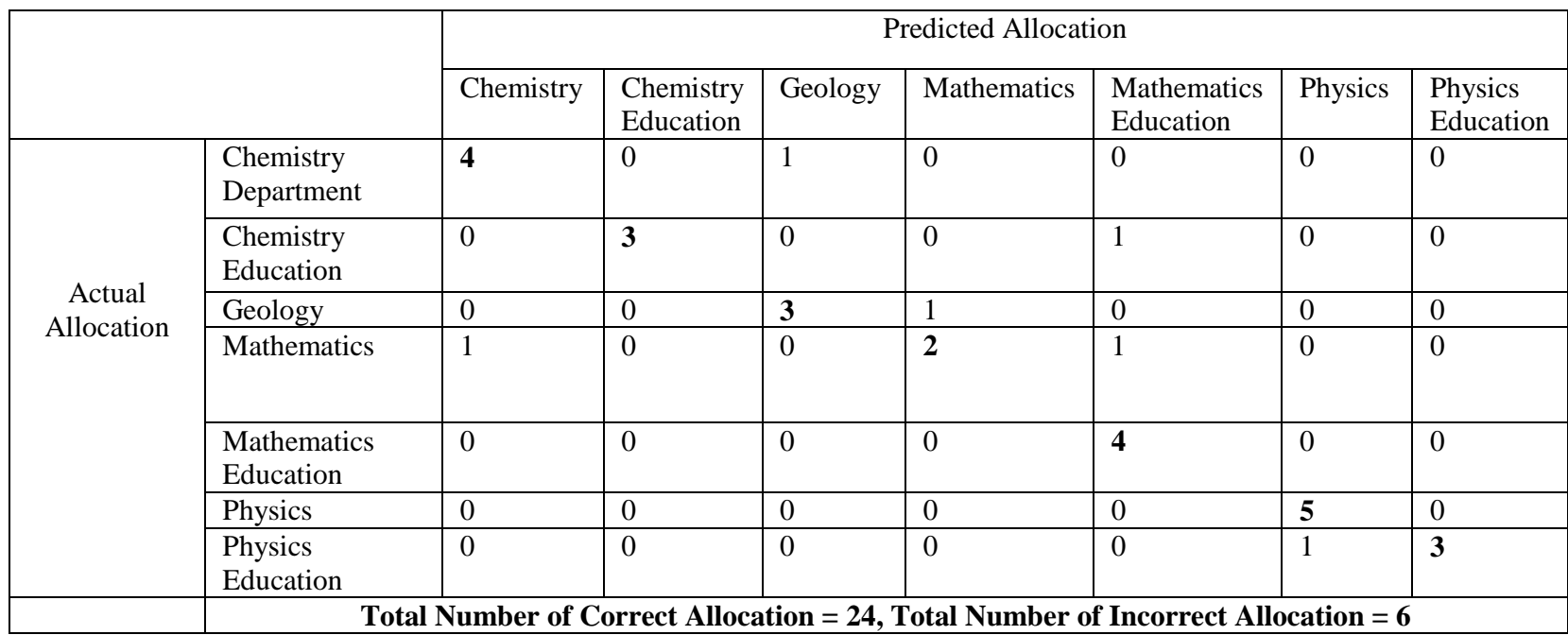

\section{EVALUATION}

The experimental evaluation of a model based on machine learning is performed according to several performance metrics. To evaluate this system, the following parameters were used: true positive (TP), false negative (FN) and false positive (FP). These were used as input to the performance metrics. The selected performance metrics for the evaluation are [23]:

a. Sensitivity or True positive rate/Recall: the proportion of relevant allocations that were correctly made by the model to the total number of allocation. This is the measure of completeness or quantity expressed as:

$$
\text { Recall }=\frac{T P}{T P+F N}
$$

b. Precision: is the proportion of correct allocations out of the total allocations made for a class. This is the fraction of retrieved allocation that are relevant. It is the measure of exactness or quality.

$$
\text { Precision }=\frac{T P}{F P+T P}
$$

Precision $_{\text {Chemistry }}=\frac{4}{1+4}=\frac{4}{5}=0.8$

Precision $_{\text {Chemistry Education }}=\frac{3}{3}=1.00$ c. Accuracy: is the percentage ratio of correct allocation to the total number of allocation.

$$
\text { Accuracy }=\frac{T P}{F P+F N+T P} \times 100
$$

The Sensitivity or Recall for each course of study was determined as follows:

$$
\begin{aligned}
& \text { Recall }_{\text {Chemistry }}=\frac{4}{1+4}=\frac{4}{5}=0.80 \\
& \text { Recall }_{\text {Chemistry Education }}=\frac{3}{1+3}=\frac{3}{4}=0.75 \\
& \text { Recall }_{\text {Geology }}=\frac{3}{1+3}=\frac{3}{4}=0.75 \\
& \text { Recall }_{\text {Mathematics }}=\frac{2}{1+1+2}=\frac{2}{4}=0.50 \\
& \text { Recall }_{\text {Mathematics Education }}=\frac{4}{4}=1.00 \\
& \text { Recall }_{\text {Physics }}=\frac{5}{5}=1.00 \\
& \text { Recall }_{\text {Physics Education }}=\frac{3}{1+3}=\frac{3}{4}=0.75
\end{aligned}
$$

The Precision of the system for each department is shown below:

$$
\begin{aligned}
& \text { Precision }_{\text {Geology }}=\frac{3}{1+3}=\frac{3}{4}=0.75 \\
& \text { Precision }_{\text {Mathematics }}=\frac{2}{1+2}=\frac{2}{3}=0.67
\end{aligned}
$$


Precision $_{\text {Mathematics Education }}=\frac{4}{1+1+4}=\frac{4}{6}=0.67$

Precision $_{\text {Physics }}=\frac{5}{1+5}=\frac{5}{6}=0.83$

Precision $_{\text {Physics Education }}=\frac{3}{3}=1.00$

Accuracy $=\frac{4+3+3+2+4+5+3}{30} \times 100=80 \%$

This result is presented in Figure 4.

\section{DISCUSSION}

From the result of the evaluation of the performance of the system, the following conclusions were drawn:

- With $80 \%$ accuracy, the system satisfies the $71 \%$ benchmark for acceptable system

- Chemistry and Physics both had the highest number of instances in the training set (20) and had the highest value for precision. Mathematics Education had the lowest number (14) and the lowest value for precision. This implies that the higher the number of instances for a course of study in the training set, the better its chances of being allocated and vice versa.

- Chemistry Education, Mathematics and Physics education have higher precision than recall, Mathematics education and Physics have higher recall than precision and the remaining two classes has equal values for recall and precision. This shows that the system has a higher probability of giving precise result.

\section{CONCLUSION}

This paper describes a system that uses artificial neural network for admission into Nigerian university through its pre-degree program.

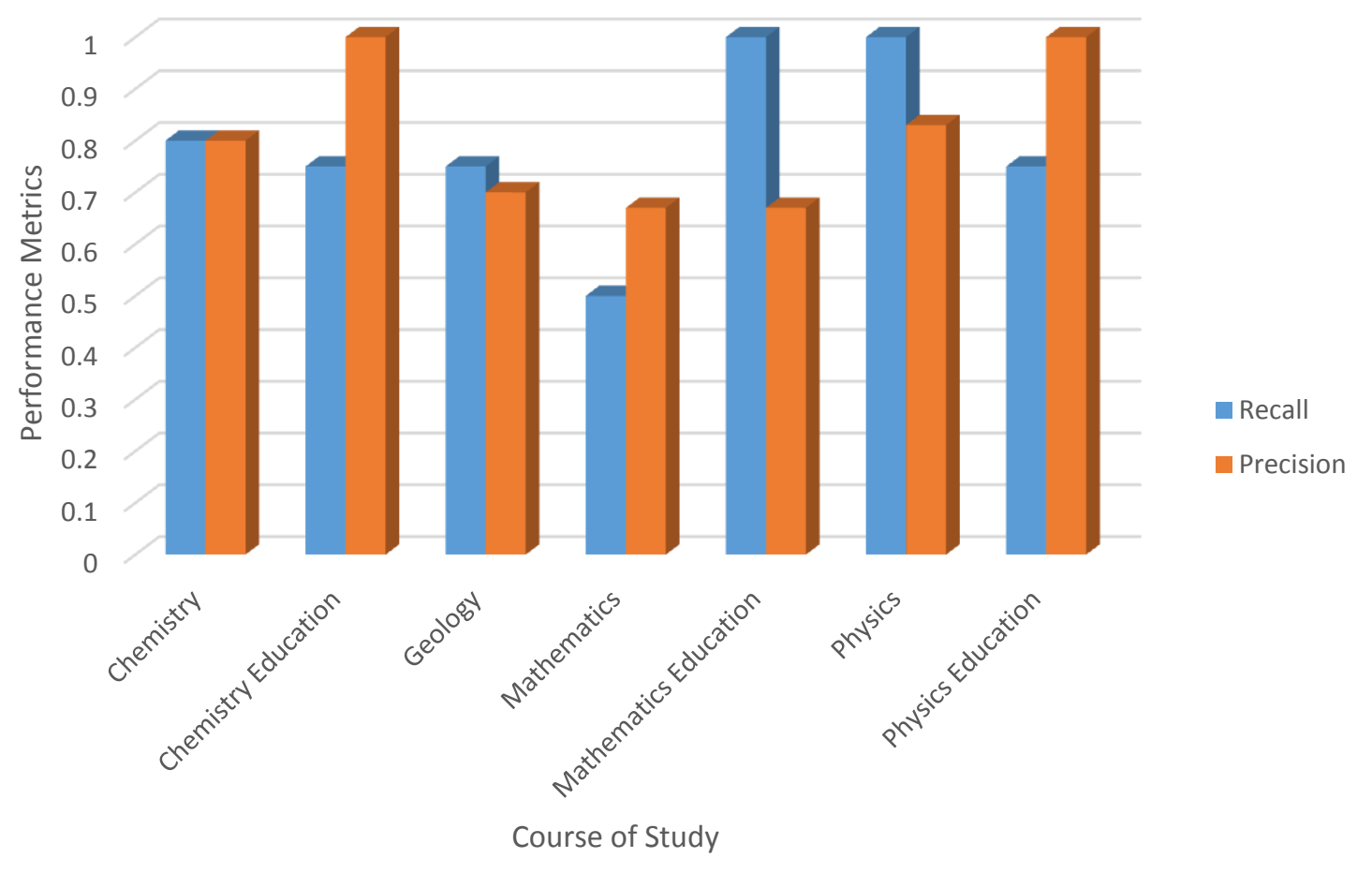

Figure 3. Result of Performance Evaluation of Resource Allocation System.

The system allocates course of study to candidates with good precision. The use of artificial intelligence in this decision making alleviates the stress encountered by the human administrator and also helps to reduce the bias associated with human intuition and judgment.

The admission process of other admission mode is presently manual and faces the same challenges. Hence, the expansion of this system to cater for other modes of admission will be considered in future works.

\section{REFERENCES}

[1] Jackson- Teague, L. (2014). Higher Education Plays Critical Role in the Society: More Women Leaders can make a Difference. Forum on Public Policy.

[2] Mansmann, S. and Scholl, M.H. (2007). Decision Support System for Managing Educational Capacity Utilization. IEEE transactions on education, Vol. 50(2). pp. 143-150.

[3] Ikono R., Babalola, A. and Iroju, O. (2017). A Resource Allocation Model for Admission into Nigerian Universities. Journal of Current Research, 9(04): 49188-49195. 
[4] Asein, J. and Lawal, Y. (2007). Admission into Tertiary Institutions in Nigeria. Annual Conference of the International Association for Educational Assessment.

[5] Diana-Abasi, I. F. (2015). Solving the problem of poor quality of university graduates in Nigeria-A proposed holistic approach. British Journal of Education, 3(7):52-70.

[6] Moti, U. G. (2010). The Challenges of Access to University Education in Nigeria. DSM Business Review, 2(2): 4-6.

[7] Wabwoba, F. and Mwakondo, F. (2011). Students Selection for University Course Admission at the Joint Admissions Board (Kenya) using Trained Neural Networks. Journal of Information Technology Education: Research, 10(1):333-347.

[8] Cruz, J. A. and Wishart, D. S. (2006). Applications of Machine Learning in Cancer Prediction and Prognosis. Cancer Informatics. 2: 59-75.

[9] Russell, S. and Norvig, P. (2003). Artificial Intelligence: A Modern Approach. Prentice hall.

[10] McConnell, C. R., Brue, S. L. and Flynn, S. M. (2011). Economics: Principle, Problems and Policies. $19^{\text {th }}$ Edition. Mc-Graw-Hill/Irwin, New York.

[11] Horny, A. S. (2001). Oxford Advanced Learner's Dictionary of Current English. $6^{\text {th }}$ Edition. Oxford: Oxford University Press.

[12] Asechemie, A. (1999). The History of the University of Port Harcourt. Port Harcourt: University of Port Harcourt press ltd.

[13] Grinager, H. (2006). How Education Technology Leads to Improved Student Achievement. Educational Issues, National Conference of State Legislatures.

[14] Meenyinikor, J. N. D. (2012). Higher Educational Resources in Nigeria: A Managerial Analysis. Global Advanced Research Journal of Educational Research and Review, 1(9): 196-201.
[15] Okebukola, P. C. (2008). Education reform: Imperatives for achieving vision 20-2020. Paper Presented at the National Summit on Education Organized by Senate Committee on Education.

[16] Mabu, A. M. and Muhammed, F. A. (2016). An Admission Decision Support System for Nigerian Universities. International Journal of Computer Applications, 133(2): 1-6.

[17] Ajayi, O. O., Ojeyinka, T. O., Isheyemi, O. G. and Lawal, M. A. (2014). A Rule-Based Higher. Institution of Learning Admission Decision support System. Journal of Information Engineering and Applications, 4(1): 7-17.

[18] Waters, A. and Miikkulainen, R. (2013). GRADE: Machine Learning Support for Graduate Admissions. In Proceedings of the 25th Conference on Innovative Applications of Artificial Intelligence. Association for the Advancement of Artificial Intelligence, 11-18.

[19] Tanna, M. (2012). Decision Support System For Admission in Engineering Colleges Based on Entrance Exam Marks. International Journal of Computer Applications, 52(11):38-41.

[20] Rojas, R. (1996). Neural Networks. Springer-Verlag, Berlin.

[21] Heaton, J. (2011). Programming Neural Networks with Encog3 in C\#. Heaton Research, Inc.

[22] Menzies, T., Greenwald, J. and Frank, A. (2007). Data Mining Static Code Attributes to Learn Defect Predictors. Institute of Electrical and Electronics Engineer Transactions on Software Engineering, 32 (1): 2-13.

[23] Sahu, R., Dash, M. and Kumar, A. (2017). Applying Predictive Analytics within the Service Sector. IGI Global Business Science Reference, Hershey, USA 